\title{
IN-BETWEEN, ACROSS, AND WITHIN DIFFERENCE: AN EXAMINATION OF "CULTURAL COMPETENCE"
}

\author{
Jonathan Morris
}

\begin{abstract}
Cultural competence" is often part of contemporary discourses of practice in child and youth care and is often referred to in curricula and documents that lay out the expected competencies of practitioners. This article represents an effort to critically examine the notion of "cultural competence", paying particular attention to how "culture" and "competence" are taken up in the literature, and how they are positioned in relation to each other in the context of practice. Efforts are made to critique the idea that "culturally competent" practice can be attained through the linear and proceduralized acquisition of pre-specified competencies. Rather, an argument is made for the development of a practice that is critically reflexive, relational, and constantly in motion while working inbetween, across, and within difference.
\end{abstract}

The purpose of this article is to critically engage with some of the current literature as it pertains to the notion of "cultural competence". The discussion will have a particular emphasis on how cultural competence is taken up in the literature and the availability of tools, strategies, and skills designed to assist practitioners in their commitments to intentional and strategic practice amidst cultural differences. It is guided by the following research questions:

1. What is the consensus definition of "cultural competence"?

2. What ideas exist about achieving individual cultural competency in practice?

Specifically, I intend to identify the central themes shared between the multiple definitions of culture, competence, and cultural competence in the literature and elucidate contemporary ideas related to the development of an individual's capacity to practice in a culturally competently manner. Furthermore, I intend to frame consideration of these two areas within a critical commentary on the state of the contemporary literature. I begin the article with a brief description of the methodology used to conduct the literature review, followed by a brief description of "critical reflexivity". I then turn to a discussion of "culture" and "competence" separately before considering the juxtaposition of "cultural competence". I conclude with some $\mid$ recommendations for practice.

\section{Methodology}

The literature review was conducted using the databases PsychInfo, Social Work Abstracts, SAGE Psychology Full-Text Collection, Social Services Abstracts, and SpringerLink. The following key words were used singularly or in combination to perform searches in the above databases: 
- Culture;

- Cultural;

- Competent and competence;

- Child and youth care;

- Counselling and counseling;

- Psychotherapy

The reference lists from articles found during the database searches provided additional sources for consideration. Further searches were completed using the Internet to consult government and private organization publications. In order to avoid omitting literature describing the historical perspectives of cultural competence, searches were not limited to any particular time period. Articles with a focus upon: (a) definitions of cultural competence; (b) principles designed to facilitate individual cultural competence development; and (c) cross-cultural interactions were included. Articles with a focus on specific ethnic, racial, or cultural groups were discarded, as the review was not designed to focus upon cultural competence with particular identified groups. The two main intellectual traditions that emerged from the search included psychology (psychotherapy, counselling, mental health) and healthcare (in-patient/outpatient service delivery, nursing).

\section{Preliminary Findings in the Literature}

The impetus for human services professionals, including child and youth care practitioners, to attain "cultural competence" in their practice has intensified over the past 25 years (Atkinson, Thompson, \& Grant, 1993; Collins \& Arthur, 2007; McPhatter \& Ganaway, 2003). Many researchers, educators, and clinicians have suggested that the increasing impetus for understanding, integration, and application of cultural competency, is linked to demographic shifts and an increasingly diverse client population (Brach \& Fraser, 2000; Pedersen \& Leong, 1997). This call to action has led to the generation of a rich and diverse literature related to cultural competency, with several U.S. researchers making considerable contributions to the knowledge base. Sue (2001) has been present in the literature since the early 1980s, theorizing about cultural competency and positing several evolving conceptual models designed to facilitate practitioner cultural development. Other notable contributors to the field include Arredondo and Toporek (2004), Pedersen and Leong (1997) and Weinrach and Thomas (2002, 2004).

The Canadian literature appears less replete than the American, but Canadian researchers Collins and Arthur (2007) have undertaken considerable work in this area, while Hoskins' (1999, 2003) thinking offers alternative ideas to the dominant competency-driven discourse. In concert with the findings of Harris (2004) who completed an international and Australian-level review of the cultural competence literature, I too observed a lack of empirical research on cultural competence with the majority of the literature focusing on descriptive, theoretical, or conceptual ideas. Harris (2004) suggests this is a result of the difficulties associated with conducting empirical research into cultural competence, and he suggests a greater emphasis upon using systematic empirical enquiry to evaluate the theoretical models presented for cultural competency development. Before considering the literature in more detail, it is perhaps useful to pause here to explain how I will engage "critically" with the literature. 


\section{Maintaining a Critically Reflexive Stance}

Mezirow (1998) asserts that critical reflection is predicated upon an understanding that knowledge is produced, not found, and that it rests upon particular epistemological foundations, all of which allow the context(s) of knowledge creation to be revealed and analysed. In addition, awareness of one's histories, biases, and assumptions about knowing speak to the adoption of a "reflexive stance" (White, 2007b). White describes the usefulness of adopting a reflexive stance when interrogating and "destabilizing taken-for-granted ideas and professional routines" (p. 215) and suggests that a critically reflexive stance can help draw one's attention to the "limits of language ... and the crude ways in which we speak and write about differences" (p. 215). Identifying myself using discrete terminology like "Western" or "non-indigenous" would be an example of this.

In relation to this paper, most of the cultural competence literature I have explored tends to "other" and create problematic binaries of "us and them" categorizations. For example, static terms such as "ethnic minorities", "racialized groups", and "disabled" inundate the literature, helping create static and reified identity categories. One can be left with a perception that culture is homogeneous or singular in nature, i.e., there is "singular" Muslim culture. Holton (2004) uses Bhaba's words when she argues that such characterizations can limit, creating boundaries that classify people and meanings forming "inescapable spaces which we all live out" (p. 1). White's (2007b) reminder of the ways language can limit or emancipate meaning is useful insight to carry throughout this discussion, as well as the understanding that I am not a "neutral observer" (p. 216), but someone who carries multiple cultural identities and assumptions of my own. Having described some of my analytical stance, I will now turn to addressing the first task: seeking meaning for the construct of "cultural competence".

\section{Understanding "Culture"}

Culture stands as a contested term as evidenced by the multiple and nuanced permutations of its definition across the literature. Amidst this multiplicity, one definition appears to appear quite frequently, and is offered up by Cross, Bazron, Dennis, and Isaacs (1989) who state that culture ". . . implies the integrated pattern of human behaviour that include thoughts, communications, actions, customs, beliefs, values, and institutions of a racial, ethnic, religious or social group" (p. 28). Cross and colleagues' definition can be contrasted with the description of cultural and human diversity contained in the Competencies for Professional Child and Youth Work Practitioners (Mattingly, Stuart, \& VanderVen, 2002) which frames culture as:

... the eight major factors which set groups apart from one another, and which give individuals and groups elements of identity: age, class, race, ethnicity, levels of ability, language, spiritual belief systems, educational achievement, and gender differences. (p. 10)

Cross et al.'s (1989) definition shifts conceptualization of culture beyond the "tip of the iceberg" (Hanley, 1999, p. 10), allowing for consideration of the elements of culture that are "hidden from view" (p. 10). Surface notions of culture might include the fine arts, dress, and cooking, while deeper aspects of culture include group decision-making processes, conceptions 
of "self", or patterns of handling emotions. Cross' inclusion of communication, thoughts, beliefs, and values are congruent with a deeper and fuller consideration of culture and its meaning. It can be argued that "deeper" concepts of culture are typically out of immediate awareness, are less visible or easy to identify, and difficult to know (Hanley). Arguably, Mattingly et al.'s (2002) articulation of culture resists further exploration, limiting culture to discrete and readily identifiable categories.

Again, the use of language in each definition emphasises the capacity for limiting or emancipating social meaning. While Cross' definition can be interpreted as more expansive and inclusive, it is clear that both tend to bind and categorize people, constructing dichotomies across pre-conceived cultural or diversity identifiers. Furthermore, the definitions help essentialize culture and assume that culture is fixed, singular, and homogenous in nature. Of note, Mattingly et al.'s definition appears to contain an error of omission, proclaiming the "eight major factors that set apart" while failing to include mention of sexual identity. Does this omission imply that sexual identity is considered a minor factor or one that bears no relation to cultural identity? In sum, both definitions constrain the meaning to be made with culture and leave questions such as: Who assigns people to belong to these groups? Can one self-determine membership to one of the ascribed categories? How can I make sense of the fact my cultural identities transect each of the categories provided?

Fitzgerald, Mullavey-O'Byrne, and Clemson (1997) provide the last definition of culture for consideration, defining culture as:

An abstract concept that refers to learned and shared patterns of perceiving and adapting to the world. Culture is reflected in its products: the learned, shared beliefs, values, attitudes, and behaviours that are characteristic of a society or population. Culture is not a static phenomenon; it is dynamic and ever-changing, but it maintains a sense of coherence. (p. 15)

This definition appears delimiting and expansive, avoiding the creation of "inescapable spaces" but emphasizing culture's existence as a variable construct. Elements of this definition can be unpacked a little further. Culture can be interpreted here as having a collective quality that helps shape the meaning made with social life and the world. This definition also implies that culture is productive in its yielding of "shared beliefs, values, attitudes, and behaviours" that can be held amongst people. The definition's emphasis on cultural elements being "characteristic of a society or population" underscores an assumption that cultural knowledge, beliefs, values, attitudes, and behaviours are not homogenous across societies or peoples (Armstrong \& Fitzgerald, 1996) with cultural interpretation being contingent upon ecological context, e.g., individuals, families, communities, regions. In a departure from the previous two cultural definitions, there is a sense of cultural fluidity and movement beyond an essentialized and "other-ed" rendering of culture, by emphasizing the dynamic and relational nature of culture.

It is important to note that broader definitions of culture such as this one have not been without controversy. Pedersen (2001) highlights the tensions between adopting a culture-specific (emic) or culture-general (etic) perspective. The earlier two definitions (Cross et al., 1989; Mattingly et al., 2002) could be described as "emic" perspectives, as they demarcate specific 
indicators that differentiate cultures. Fitzgerald et al.'s (1997) efforts are "etic" in nature. Pedersen (1984, as cited in Pedersen, 2001) explains that complexity arises when counsellors attempt to describe behaviours in terms that are true to a particular culture, while at the same time comparing those behaviours with a similar pattern in one or more cultures. Instead of dichotomizing the "etic" and "emic" approaches to understanding culture, Pedersen suggests blending the two to avoid "cultural encapsulation" where counsellors" practice is predicated upon their own culture-specific assumptions.

\section{Understanding "Competence"}

As the discussion above has shown, there are multiple ways of defining, understanding, and making meaning with culture in practice. Conversely, arriving at a mutually understood definition of competence appears a lot more straightforward. The word competence offers a sense of absoluteness, certainty, and clarity, invoking ideas of mastery, proficiency, and efficacy. White (2007a) locates competency within the technical-rational paradigm, imbued by an "instrumental-view of practice", whereby, "knowledge is acquired, skills are mastered, attitudes are adopted, self-awareness is gained, and then these things are applied to children, youth, families and communities" (p. 230). In many ways, the technical-rational paradigm of competence allays the natural anxiety I feel as a practitioner, when trying to comprehend the nuance and complexity of culture and its implications for CYC practice. Specifically, competence imparts the perception that culturally competent/sensitive/responsive practice is indeed attainable if appropriate steps are followed, requisite knowledge is acquired, and the boxes are ticked. McKee Sellick, Delaney, and Brownlee (2002) problematize the allure of certainty afforded by the technical-rational paradigm:

Increasing scrutiny and pressure from agency administrators, insurance providers, and consumers to prove that we know what we are doing and that what we are doing really works, makes us susceptible to the clarion call of the empirical practice and evidencebased practice movements. Their certainty is seductive, an answer to our desire for real competence. (p. 493)

Harris (2004) argues that if Fitzgerald et al.'s (1997) expansive definition of culture is coupled with "competence", a deeper and more complex meaning can be inferred. I would argue that such a shift in meaning requires deliberate attention and the principles of Pendlebury's "perceptive equilibrium" (White, 2007a, p. 230), where procedural principles (i.e., competency areas) are afforded equal consideration to the contextual particulars of a practice situation (e.g., political, historical, social influences). Moreover, I resist the idea of "attaining" cultural competence as being the meeting of a pre-specified standard or level. Rather, instead of a quantifiable outcome, culturally competent practice exists on a continuum of process, where one pays particular attention to understanding, integrating, and applying practices that are as relational, collaborative, and culturally responsive as possible.

\section{Understanding "Cultural Competence"}

Having devoted some time to describing and critically reflecting upon the definitions of "culture" and "competence" separately, I will now attend to describing the literature's definitions 
of the "cultural competence". From a historical perspective, some have argued the origins of cultural competence lie with Dr. Carter G. Woodson, often regarded as the "Father of Black History". His message was that Blacks should carry pride in their history, and reciprocally, society as a whole should understand Black History (Hanley, 1999). Woodson's aim in calling on people to understand their histories and contributions to society was to increase peoples' selfesteem, leading to other cultures feeling better and "accepting", hence causing greater intragroup acceptance and a subsequent reduction in racism and oppressive practices (Hanley). Several of the tenets of contemporary cultural competency are present in Woodson's ideology, which can be emphasised by considering a more recent definition.

Brach \& Fraser (2000) draw attention to Cross et al.'s seminal work on increasing cultural competency in settings serving emotionally disturbed children and youth, which advocates for recognition of "strengths inherent in all cultures" (Cross et al., 1989, p. 18). Cross et al.'s ideas of cultural competence transverse from the individual practitioner, to their agency, to broader systems and society itself, all with the central aim of providing culturally-responsive practice to best support racially diverse children and youth. The anecdotes Cross and colleagues provide serve to highlight the inequities of treatment in the mental health, youth justice, and child welfare systems 20 years ago, and the associated impetus for culturally competent practice. There are striking similarities to the state of affairs 20 years later:

If you are an adolescent and Black and you are seriously emotionally disturbed, chances are you will end up in the juvenile justice system rather than in the treatment setting to which your Caucasian counterpart would be referred. If you are a Native American child and seriously emotionally disturbed, you will likely go without treatment or be removed legally and geographically from your family and tribe. If you are a child who is Hispanic and seriously emotionally disturbed, you will likely be assessed in a language not your own. And if you are an Asian child and seriously emotionally disturbed, you will likely never come to the attention of the mental health system. (p.19)

It is clear Cross and colleagues (1989) wanted to respond to gross disparities in treatment settings for culturally diverse groups. The catalyst for change has been explicated. How does one move forward? Cross et al. (1989) created a continuum of cultural competence that will perhaps offer some perspective to the journey of developing intentionality in one's practice amidst diversity. The continuum can be applied both at the individual and agency levels. For this purposes of this paper, the focus will be upon locating the individual along the spectrum.

The continuum starts at cultural destructiveness typified by attitudes, policies, and practices that are destructive to cultures and the people who make meaning with them (Cross et al.). Cultural genocide (e.g., residential schools and indigenous populations), dehumanizing or subhumanizing clients, or conducting experiments that risk the health and safety of cultural groups all serve as examples of efforts to disenfranchise, control, exploit, or systematically destroy those that are perceived to be different (Cross et al.).

According to Cross and colleagues (1989), cultural incapacity is typified not by intentional cultural destruction, but by a lack of capability to respond to cultural diversity. Individuals or agencies subscribe to the discourse that the "dominant" cultural group is 
"superior", while adopting a paternalistic stance to "inferior" groupings or individuals.

Moreover, there is a belief that helping practices located within the "dominant" cultural group are more effective than alternatives. Oppression and discrimination are endemic at this stage of the continuum, with practitioners holding lower expectations of clients with diverse cultural identities.

During cultural blindness, practitioners and agencies subscribe to the belief that no difference exists between people (Cross et al., 1989). Arguments of universality and generalizability are applied to the helping approaches typically used by the "dominant" culture, with the assumption that everyone can be served with equal effectiveness. Ethnocentrism persists along with the continued push for assimilation. Other notable characteristics include ignorance of cultural strengths, victimization, and endemic institutionalized oppression and discrimination.

The first sign of movement or progress takes place when individuals or agencies reach the pre-competence stage. Cross et al. (1989) suggest individuals/agencies develop an awareness of inadequate service delivery, start to experiment with change by hiring culturally diverse practitioners, conduct needs assessments, and recruit culturally diverse representatives to their governance structures. Hence, there is a likelihood of tokenistic hiring practices. Cross et al. convey optimism that at this point a forward progression is starting; agencies or practitioners are just lacking accurate information about how to proceed next.

At the stage of cultural competence, Cross et al. describe characteristics of "acceptance and respect for differences" (p. 32) with practitioners and agencies attending to continued selfassessment, inter and intra cultural dynamics, expansion of culturally appropriate resources, and adapted service delivery models. Tokenistic hiring has ceased and practitioners demonstrate an ability to relate to, collaborate with, and respond to a culturally diverse world, while ensuring culturally responsive policies and regulations are translated into practice.

Finally, cultural proficiency is a transition toward "holding culture in high esteem" (Cross et al., 1989, p. 32), whereby practitioners and agencies actively contribute to the culturally competent knowledge base, construct knowledge in relation to interventions and treatments, and disseminate those findings for others to utilize. Hallmark characteristics include hiring specialists in culturally competent practice and strategic advocacy for systemic and societal change with respect to cultural diversity.

Cross et al.'s (1989) continuum provides the necessary foreground for defining "cultural competence", which they state as follows:

Cultural competence is set of congruent behaviours, attitudes, and policies that come together in a system, agency, or among professionals and enable that system, agency, or those professionals to work effectively in cross-cultural situations. (p. 28)

\section{Critical Commentary}

Both Cross et al.'s (1989) model and their definition provide a useful starting place from which to take the necessary steps toward developing cultural competence in practice, but several 
questions remain. The continuum as presented resembles a linear and sequential actualization of higher states of competency; it might be useful to include consideration of the dynamics of individuals or agencies that oscillate between stages. Notably, the continuum leaves culture open to interpretation, but there are implicit themes suggesting the model is designed to respond to racial and ethnic diversity. This may be related to the historical, political, and social context to which it was originally applied, but would similar processes exist if other cultural identities were applied?

The literature suggests that researchers have attempted to address some of these limitations. McPhatter and Ganaway (2003) apply Diclemente's and Prochaska's Transtheoretical Model of Change to Cross et al.'s (1989) continuum, which helps explicate not only one's own stage of change in relation to moving toward cultural competency, but presents a means of assessing readiness for change across groups of practitioners or managers within an agency. Recognition of the variability within individuals' and agencies' ability to move forward with change, can help create the necessary conversational space to establish the barriers in operation and strategies for facilitating the most effective change process possible. McPhatter \& Ganaway also present their own definition of cultural competence:

Cultural competence is the ability to transform knowledge and cultural awareness into health and/or psychosocial interventions that support and sustain healthy client-system functioning within the appropriate cultural context. (p. 105)

In comparing the two presented definitions, McPhatter \& Ganaway (2003) operationalize Cross et al.'s (1989) further, emphasising the transition between knowledge acquisition and knowledge utilization, breaking "effective practice" down into "interventions" that promote "health". I would like to see a thickening of both definitions, specifically to illuminate the didactic and relational interface between cultural identities, and the subsequent reciprocal influence upon the practitioners themselves.

To summarize this particular critical commentary, I would like to attend to the view of practice that is being taken up by both definitions. As White (2007a) states, ". . . the assumption that the complexity of practice - and professional development - can be adequately conceptualized and measured by discrete 'outputs' like knowledge, skills, and attitudes can be highly problematic" (p. 230). Arguably, Cross et al.'s (1989) continuum and definition, and McPhatter's and Ganaway's (2003) definition take up a narrowly defined view of practice that is predicated upon procedural and routinized acquisition of knowledge. The problem lies in the arguably messy, uncertain, and unpredictable nature of practice situations and whether such "technical solutions" can be applied to the "swampy lowlands" of day-to-day practice (Schön, 1987, p. 1).

\section{Conclusions and Recommendations}

By way of conclusion, throughout the course of this literature review, I have described several salient definitions of culture, competence, and cultural competence. I have maintained a stance of critical reflexivity in an attempt to interrogate and reveal some of the hidden assumptions embedded within the claims made in the literature. First, several themes related to 
defining culture emerged in the literature: (a) culture is relational and fluid, providing frames of reference for negotiating the world; (b) culture is systemic, occurring within, between, and across individuals, families, communities, and regions; (c) each individual carries culture - culture is not simply a construct applied to "others" apart from "us"; and (d) culture embodies heterogeneity, carries temporal qualities, and cannot be singularized. Second, particular attention should be paid to the problems related to seeing "competence" as an end-point in the journey to practicing ethically, relationally, and responsively amidst diversity. Rather than being seen narrowly as routinized or procedural, competence in this context can be seen as an organic process requiring a critically reflective stance to continued learning. Third, it is perhaps useful to frame cultural competence within a cyclical continuum, with different indicators to mark changes in the journey of developing culturally competent practice. A useful addition to the continuum are the stages of change, which may help create conversational spaces to identify obstacles to the process of moving forward. Again, it is important to respect the procedural principles of such schemas, but equally important to consider the particular contextual nuances of the everyday practice situation. 


\section{References}

Armstrong, M. J., \& Fitzgerald, M. H. (1996). Culture and disability studies: An anthropological perspective. Rehabilitation Education, 10(4), 247-304.

Arredondo, P., \& Toporek, R. (2004). Multicultural counseling competencies = ethical practice. Journal of Mental Health Counseling, 26(1), 44-55.

Atkinson, D. R., Thompson, C. E., \& Grant, S. K. (1993). A three-dimensional model for counseling racial/ethnic minorities. The Counseling Psychologist, 21(2), 257-277.

Brach, C., \& Fraser, I. (2000). Can cultural competency reduce racial and ethnic health disparities: A review and conceptual model. Medical Care Research and Review, 57(1), 181-217.

Collins, S., \& Arthur, N. (2007). A framework for enhancing multicultural counselling competence. Canadian Journal of Counselling, 41(1), 31-49.

Cross, T., Bazron, B. J., Dennis, K. W., \& Isaacs, M. R. (1989). Toward a culturally competent system of care: A monograph on effective services for minority children who are severely emotionally disturbed. Washington, DC: Georgetown University Child Development Center.

Fitzgerald, M. H., Mullavey-O’Byrne, C., \& Clemson, L. (1997). Cultural issues from practice. Australian Occupation Therapy Journal, 44, 1-21.

Hanley, J. (1999). Beyond the tip of the iceberg: Five steps toward cultural competence. Reaching Today's Youth, 3(2), 9-12.

Harris, P. (2004). Culturally competent disability support: Putting it into practice. Retrieved on July 9, 2010, from www.mdaa.org.au.

Holton, T. (2004). Suicidology and the "other": A discursive analysis of literature and discourses. (Doctoral dissertation, University of Calgary, 2005). Amicus Abstracts, 31075197.

Hoskins, M. (1999). Worlds apart and lives together: Developing cultural attunement. Child \& Youth Care Forum, 28(2), 73-85.

Hoskins, M. (2003). What unites us, what divides us? A multicultural agenda within child and youth care. Child \& Youth Care Forum, 32(6), 319-336.

Mattingly, M., Stuart, C., \& VanderVen, K. (2002). Competencies for professional child and youth work practitioners. Journal of Child and Youth Care Work, 17, 16-49. 
McKee Sellick, M., Delaney, R., \& Brownlee, K. (2002). The deconstruction of professional knowledge: Accountability without authority. Families in Society: The Journal of Contemporary Human Services, 83(5/6), p. 493-498.

McPhatter, A., \& Ganaway, T. (2003). Beyond the rhetoric: Strategies for implementing culturally effective practice with children, families, and communities. Child Welfare League of America, 82(2), 103-124.

Mezirow, J. (1998) On critical reflection. Adult Education Quarterly, 48(3), 185-198.

Pedersen, P., \& Leong, F. (1997). Counseling in an international context. The Counseling Psychologist, 25(1), 117-122.

Pedersen, P. B. (2001). Multiculturalism as a generic approach to counseling. Journal of Counseling and Development, 70, 6-12.

Schön, D. (1987). Educating the reflective practitioner. San Francisco, CA: Jossey-Bass.

Sue, D. W. (2001). Multidimensional facets of cultural competence. The Counseling Psychologist, 29(6), 790-821.

Weinrach, S. G., \& Thomas, K. R. (2002). A critical analysis of the multicultural counseling competencies: Implications for the practice of mental health counseling. Journal of Mental Health Counseling, 24(1), 20-35.

Weinrach, S. G., \& Thomas, K. R. (2004) The AMCD multicultural counseling competencies: A critically flawed initiative. Journal of Mental Health Counseling, 26(1), 81-93.

White, J. (2007a). Knowing, doing, and being in context: A praxis-oriented approach to child and youth care. Child \& Youth Care Forum, 36(5), 225-244.

White, J. (2007b). Working in the midst of ideological and cultural differences: Critically reflecting on youth suicide prevention in indigenous communities. Canadian Journal of Counselling, 41(4), 213-227.

Jonathan Morris has, over the past ten years, practiced across several contexts in child and youth care including programs for children responding to violence at home, hospital-based psychiatric treatment, school-based youth suicide prevention education, and campus mental health promotion. Jonathan has taught in the undergraduate child and youth care program at the University of Victoria and is nearing the completion of his M.A. degree. His graduate research explores how the ideas of Michel Foucault can be used to critically examine youth suicide prevention curricula. Other scholarly interests include the role of communities of practice in campus mental health promotion and narrative-informed approaches to child and youth care work. 